\section{Retinal dialysis: are we missing diagnostic opportunities?}

\begin{abstract}
Aims To review medical records of those patients managed by our department for retinal dialysis, and establish whether the initial assessment had been adequate to make the diagnosis. That is, to establish if an adequate initial assessment had been performed that would reasonably exclude the likelihood of retinal dialysis and other trauma-related sequelae such as angle recession.
\end{abstract}

Methods A retrospective review was made of all patients managed for retinal dialysis at Sussex Eye Hospital between 20 March 1997 and 20 September 2002 (66 months). In addition to general demographic data, surgical management and outcome, patient files were reviewed for history of trauma, prior ophthalmic review, and whether such review included documentation of peripheral retinal examination and gonioscopy.

Results A total of 580 primary procedures were performed for retinal detachment during the review period, of which 32 eyes of 29 patients underwent surgery for retinal dialysis (6\%). There were 21 male and eight female patients, with a history of trauma obtained in $55 \%$ (17 eyes, 16 patients). Of the 16 patients with prior trauma, nine had undergone prior ophthalmic review at the time or soon after their trauma; however, only $2(22 \%)$ had documented evidence of indented peripheral retinal examination. Only one $(3 \%)$ patient in the whole series had documented gonioscopy. Conclusions Patients with history of trauma often present at the time or soon after their injury (eg hyphaema, orbital fractures). Thus, an opportunity exists to screen patients for known sequelae of trauma such as retinal dialysis and angle recession. It was disappointing to learn that this opportunity was not always being utilized, with some patients consequently developing macula-off

BJ Vote and AG Casswell

retinal detachments and potential for reduced visual outcome.

Eye (2004) 18, 709-713. doi:10.1038/sj.eye.6701310

Published online 20 February 2004

Keywords: retinal dialysis; blunt trauma; audit indentation; gonioscopy

\section{Introduction}

A retinal dialysis is a tear in the retina whose anterior edge is at the ora serrata and whose posterior edge is attached to the vitreous base. ${ }^{1}$ The majority of patients presenting for surgical management of retinal dialysis are known to have a significant past history of trauma to the affected eye. ${ }^{1-6}$

Blunt contusion trauma to the globe is also recognised to cause anterior segment trauma especially angle recession, which can lead to ocular hypertension and glaucoma. ${ }^{5,7-10}$

Patients with posterior segment pathology frequently have normal visual acuity, and although retinal and drainage angle pathology secondary to blunt trauma is more likely in patients presenting with hyphaema, the severity of anterior segment injury is not a good predictor of posterior segment damage. ${ }^{10}$ Thus, early peripheral retinal and gonioscopic examination has been previously identified as important in preventing morbidity after ocular trauma, with visual prognosis worse in patients who escape initial examination or are lost to follow-up. ${ }^{5,9-11}$

We were interested in reviewing whether patients managed in our unit for retinal dialysis had undergone prior ophthalmic review, and if so, whether an adequate initial assessment had been performed that would reasonably exclude the likelihood of retinal dialysis or angle recession (ie indented peripheral fundus examination and gonioscopy).
Department of Ophthalmology Sussex Eye Hospital Brighton, UK

Correspondence: AG Casswell Department of Ophthalmology Sussex Eye Hospital Brighton BN2 5BF, UK Tel: +441273606126 Fax: + 441273693674 E-mail: a.casswell@ mistral.co.uk

Received: 5 April 2003 Accepted in revised form: 18 August 2003 Published online: 20 February 2004

The authors have no financial interest in any of the instruments or techniques used in this manuscript. 
Table 1 Summary of retinal dialysis patient data

\begin{tabular}{|c|c|c|c|c|c|c|c|c|c|c|}
\hline $\begin{array}{l}\text { Patient } \\
\text { no. }\end{array}$ & $\operatorname{Sex}$ & $\begin{array}{l}\text { Age } \\
\text { (years) }\end{array}$ & Side & Location & Trauma & $\begin{array}{l}\text { Mechanism } \\
\text { (all vs } \\
\text { affected eye) }\end{array}$ & $\begin{array}{l}\text { Time from } \\
\text { injury to } \\
\text { dialysis } \\
\text { presenting }\end{array}$ & $\begin{array}{l}\text { Prior } \\
\text { ophthal. } \\
\text { review }\end{array}$ & $\begin{array}{l}\text { If trauma } \\
\text { history but } \\
\text { not seen } \\
\text { prior-reason } \\
\text { given by patient }\end{array}$ & $\begin{array}{l}\text { Clinical problems } \\
\text { seen at prior } \\
\text { review/initial injury }\end{array}$ \\
\hline 1 & $\mathrm{M}$ & 27 & $\mathrm{~L}$ & Temp & No & & & No & & \\
\hline \multirow[t]{2}{*}{2} & $\mathrm{~F}$ & 21 & $\mathrm{R}$ & Sup-temp & No & & & No & & \\
\hline & $\mathrm{F}$ & 21 & $\mathrm{~L}$ & Inf-temp & No & & & No & & \\
\hline 3 & $\mathrm{~F}$ & 20 & $\mathrm{R}$ & Inf-temp & No & & & Yes & & \\
\hline 4 & $\mathrm{~F}$ & 35 & $\mathrm{R}$ & Inf-temp & No & & & Yes & & \\
\hline 5 & M & 34 & $\mathrm{~L}$ & Sup-temp & No & & & No & & \\
\hline 6 & M & 38 & $\mathrm{R}$ & Inf-temp & No & & & Yes & & \\
\hline 7 & $\mathrm{~F}$ & 33 & $\mathrm{~L}$ & Inf-temp & No & & & No & & \\
\hline 8 & M & 49 & $\mathrm{R}$ & Inf-temp & No & & & No & & \\
\hline 9 & M & 49 & $\mathrm{R}$ & Inf-temp & No & & & No & & \\
\hline 10 & $\mathrm{~F}$ & 25 & $\mathrm{R}$ & Inf-temp & No & & & Yes & & \\
\hline 11 & $\mathrm{M}$ & 40 & $\mathrm{R}$ & Inf & No & & & Yes & & \\
\hline 12 & $\mathrm{M}$ & 39 & $\mathrm{~L}$ & Inf-temp & No & & & No & & \\
\hline 13 & $\mathrm{M}$ & 16 & $\mathrm{~L}$ & Inf-temp & No & & & No & & \\
\hline \multirow[t]{2}{*}{14} & M & 48 & $\mathrm{~L}$ & Inf-temp & No & & & No & & \\
\hline & M & 48 & $\mathrm{R}$ & Inf-temp & Yes & Squash & 9 years & No & Vision unaffected & \\
\hline \multirow[t]{2}{*}{15} & M & 38 & $\mathrm{~L}$ & Inf-temp & Yes I & Not specified & 1 month & Yes & & Normal initial examination \\
\hline & M & 38 & $\mathrm{R}$ & Inf-temp & Yes 1 & Not specified & 1 month & Yes & & Normal initial examination \\
\hline 16 & $\mathrm{~F}$ & 50 & $\mathrm{~L}$ & Inf-temp & Yes 1 & Fell on to skipole & 6 months & No & $\begin{array}{l}\text { Bruised eye and cheek } \\
\text { but normal vision next } \\
\text { day (was on holiday) }\end{array}$ & \\
\hline 17 & $\mathrm{M}$ & 25 & $\mathrm{~L}$ & Inf-temp & Yes 1 & Hockey ball & 1 month & Yes & & $\begin{array}{l}\text { Hyphaema, mydriasis,lid } \\
\text { swelling/cut }\end{array}$ \\
\hline 18 & M & 29 & $\mathrm{~L}$ & Inf-temp & Yes 1 & Punch & 1 month & No & Vision unaffected & \\
\hline 19 & M & 21 & $\mathrm{~L}$ & Inf-temp & Yes 1 & Punch (boxer) & 2 months & Yes & & $\begin{array}{l}\text { Vitreous pigment seen, normal } \\
\text { slit lamp fundal examination }\end{array}$ \\
\hline 20 & M & 22 & $\mathrm{~L}$ & Inf & Yes 1 & Explosion & 0 months & No & Seen at presentation & $\begin{array}{l}\text { Conj lac'n, commotio macula, inf } \\
\text { angle recession, choroid rupture } \\
\text { hyphaema }\end{array}$ \\
\hline 21 & M & 30 & $\mathrm{R}$ & Sup-nasal & Yes & Assault & 1 month & Yes & & Microhyphaema, IOP40mmHg \\
\hline 22 & M & 35 & $\mathrm{~L}$ & Nasal & Yes & Ball-bearing & 3 weeks & Yes & & Conjunctival laceration \\
\hline 23 & $\mathrm{M}$ & 42 & $\mathrm{R}$ & Inf-temp & Yes 1 & Kick (rugby) & 28 years & Yes & & $\begin{array}{l}\text { Dialysis followed for } 2 \text { years } \\
\text { without treatment }\end{array}$ \\
\hline 24 & $\mathrm{M}$ & 22 & $\mathrm{~L}$ & Inf-temp & Yes & Alleged assault & 5 years & No & $\begin{array}{l}\text { Drug addict did not } \\
\text { seek care after injury }\end{array}$ & \\
\hline 25 & M & 15 & $\mathrm{~L}$ & Sup-nasal & Yes & $\begin{array}{l}\text { Severe } \\
\text { blunt-unspecified }\end{array}$ & 1 month & Yes & & $\begin{array}{l}\text { Traumatic mydriasis, severe } \\
\text { macula commotio }\end{array}$ \\
\hline 26 & $\mathrm{~F}$ & 41 & $\mathrm{~L}$ & Inf-temp & Yes & Golf club & 2 years & Yes & & Normal initial examination \\
\hline 27 & $\mathrm{M}$ & 19 & $\mathrm{~L}$ & Inf-temp & Yes 1 & Kick (rugby) & 2 years & No & $\begin{array}{l}\text { Normal vision but } \\
\text { black eye }\end{array}$ & \\
\hline 28 & M & 36 & $\mathrm{~L}$ & Sup-temp & Yes & Alleged assault & 1 month & Yes & & $\begin{array}{l}\text { Scleral lac'n/rupture suptemp } \\
\text { circum, soft eye deep AC, } \\
\text { hyphaema, vit haem }\end{array}$ \\
\hline 29 & $\mathrm{~F}$ & 58 & $\mathrm{R}$ & Inf-nasal & Yes $\mathrm{I}$ & $\begin{array}{l}\text { Facial/orbital } \\
\text { injuries after RTA }\end{array}$ & 3 weeks & Yes & & $\begin{array}{l}\text { Total hyphaema, subluxed lens, } \\
\text { vit haem, incr IOP }\end{array}$ \\
\hline
\end{tabular}

\section{Methods}

A retrospective review was made of all patients managed for retinal dialysis at Sussex Eye Hospital between 20 March 1997 and 20 September 2002 (66 months). Patients were identified from a prospectively maintained surgical database and subsequent case record analysis performed. General demographic data and surgical management and outcome (visual acuity and retinal reattachment) data were obtained. In addition, patient files were reviewed for: history of trauma; prior ophthalmic review; whether such review included documentation of 
Table 1 (continued)

\begin{tabular}{|c|c|c|c|c|c|c|c|c|c|}
\hline $\begin{array}{l}\text { Indented } \\
\text { peripheral } \\
\text { retinal } \\
\text { examination }\end{array}$ & $\begin{array}{l}\text { Gonio- } \\
\text { scopy }\end{array}$ & $\begin{array}{l}\text { Ocular } \\
\text { hypertension } \\
\text { requiring } \\
\text { treatmentat } \\
\text { finalfollow- } \\
\text { up }\end{array}$ & $\begin{array}{l}\text { Macula- } \\
\text { on }\end{array}$ & $\begin{array}{c}\text { Presenting } \\
\text { VA }\end{array}$ & $\begin{array}{c}\text { Final } \\
V A\end{array}$ & $\begin{array}{l}\text { Follow-up } \\
\text { (months) }\end{array}$ & $\begin{array}{l}\text { First } \\
\text { procedure } \\
\text { notes }\end{array}$ & $\begin{array}{l}\text { Further } \\
\text { proc notes }\end{array}$ & $\begin{array}{l}\text { Successful } \\
\text { reattachment }\end{array}$ \\
\hline No & No & No & No & $6 / 24$ & & & Cryo/276/C3F8 & & Yes \\
\hline No & No & No & No & $6 / 60$ & $6 / 60$ & 1 & Cryo/276 & Vity/cryo/276/SF6 & Yes \\
\hline No & No & No & Yes & $6 / 9$ & $6 / 6$ & 1 & Cryo & & Yes \\
\hline Yes & No & No & Yes & $6 / 6$ & $6 / 9$ & 57 & Cryo/240/276/ext drain & Laser barrier & Yes \\
\hline No & No & No & No & $6 / 24$ & $6 / 18$ & 13 & Cryo/276/ext drain & & Yes \\
\hline No & No & No & Yes & $6 / 6$ & $6 / 6$ & 56 & Cryo/276 & & Yes \\
\hline Yes & No & No & Yes & $6 / 6$ & $6 / 5$ & 2 & Cryo/276/ext drain & & Yes \\
\hline No & No & No & No & $\mathrm{CF}$ & $\mathrm{CF}$ & 3 & Cryo/276/ext drain & & Yes \\
\hline No & No & No & Yes & $6 / 6$ & $6 / 6$ & 23 & Cryo/276/ext drain/SF6 & & Yes \\
\hline No & No & No & Yes & $6 / 18$ & $6 / 12$ & 3 & Cryo/276/ext drain/SF6 & Cryo/276/ext drain & Yes \\
\hline Yes & No & No & Yes & $6 / 6$ & $6 / 6$ & 2 & Cryo/277 & & Yes \\
\hline No & No & No & No & $6 / 18$ & $6 / 9$ & 5 & Cryo/277 & 277/240/cryo/ext drain & Yes \\
\hline No & No & No & Yes & $6 / 5$ & $6 / 6$ & 13 & Cryo/277/ext drain & & Yes \\
\hline No & No & No & No & $6 / 36$ & $6 / 18$ & 19 & Cryo/5mm sponge & & Yes \\
\hline No & No & No & Yes & $6 / 9$ & $6 / 6$ & 33 & Cryo/276/ext drain & & Yes \\
\hline No & No & No & Yes & $6 / 6$ & $6 / 5$ & 33 & Cryo/276/ext drain & & Yes \\
\hline No & No & No & Yes & $6 / 18$ & $6 / 5$ & 6 & Cryo/276/ext drain & & Yes \\
\hline No & No & No & Yes & $6 / 9$ & $6 / 5$ & 6 & Cryo/276 & & Yes \\
\hline No & No & No & Yes & $6 / 9$ & $6 / 12$ & 2 & Cryo/240/276/ext drain & & Yes \\
\hline No & No & No & Yes & $6 / 6$ & $6 / 5$ & 13 & Cryo & & Yes \\
\hline No & No & No & No & HM & $6 / 24$ & 30 & Cryo/276 & & Yes \\
\hline No & No & No & Yes & $6 / 9$ & $6 / 9$ & 1 & Cryo/276 & & Yes \\
\hline No & Yes & No & Yes & $6 / 24$ & $6 / 12$ & 3 & Cryo/276 & & Yes \\
\hline No & No & Yes & Yes & $6 / 24$ & $6 / 24$ & 3 & Cryo/276 & Cryo/277/240/ext drain & Yes \\
\hline No & No & No & Yes & $6 / 5$ & $6 / 6$ & 1 & Cryo/276/ext drain/SF6 & Laser barrier & Yes \\
\hline Yes & No & No & Yes & $6 / 5$ & $6 / 6$ & 16 & Cryo/276/ext drain & & Yes \\
\hline No & No & No & No & $\mathrm{CF}$ & $\mathrm{CF}$ & 1 & Cryo/276/ext drain & Vity/LIO/C3F8 gas & Yes \\
\hline Yes & No & No & Yes & $6 / 60$ & $6 / 36$ & 7 & Cryo/276/ext drain/SF6 & & Yes \\
\hline No & No & No & No & $\mathrm{CF}$ & $6 / 12$ & 1 & Cryo/277 & & Yes \\
\hline No & No & No & No & $6 / 18$ & $6 / 18$ & 15 & Cryo/sponge & Remove sponge & Yes \\
\hline $\begin{array}{l}\text { N/A as } \\
\text { primary } \\
\text { repair of } \\
\text { open eye } \\
\text { required }\end{array}$ & No & No & Yes & $6 / 60$ & $6 / 6$ & 28 & Vity/cryo/oil/276 & Phaco + IOL/remove OIL & Yes \\
\hline No & No & Yes & Yes & PL & HM & 35 & Vity/laser/lensectomy & Cryo/276 & Yes \\
\hline
\end{tabular}

indented peripheral retinal examination and gonioscopy; the time between their initial ophthalmic review and presentation with dialysis; and any evidence of fellow eye pathology. Indented peripheral retinal examination was considered to have occurred if either documented as such in the notes, if comment made on the state of ora serata (normal or otherwise), or if comment made indicating presence/absence of dialysis. The absence of documentation regarding peripheral retinal state was considered as evidence that no indented examination had occurred.

\section{Results}

A total of 580 primary procedures were performed at Sussex Eye Hospital for retinal detachment during the review period, of which 32 eyes of 29 patients underwent surgery for retinal dialysis $(6 \%)$ (see Table 1 for summary of patient data). There were 21 male and eight female patients with mean age of 33 years (male subjects: 32 years; female subjects: 35 years), and mean follow-up of 13.5 months (range $0-57$ ). A history of trauma was 
obtained in 55\% (17 eyes, 16 patients), 12/19 left eyes and $5 / 13$ right eyes. Three patients underwent bilateral procedures for retinal dialysis, two of which gave a history of trauma. Of the 16 patients with a history of trauma, 10 had undergone prior ophthalmic review at the time or soon after their trauma. One patient (no. 28) had required primary repair of globe rupture elsewhere, and the issue of prior indented peripheral retinal examination was considered not applicable in this case. All 9 remaining patients had been reviewed in our ophthalmic casualty unit, initially by either senior house officers or staff grade specialists. Each of these patients had been seen on at least one occasion between presenting with their trauma and presenting with retinal detachment due to dialysis; however, only two (22\%) had documented evidence of indented peripheral retinal examination. Only one (3\%) patient managed for retinal dialysis had documented gonioscopy performed at any time in their management. Elevated IOP requiring medical control was noted in two $(6 \%)$ patients.

All nasal dialyses were associated with trauma, while trauma was reported in only $50 \%$ for dialyses at other sites. Inferiorly and/or temporally was the commonest dialysis site, which is in keeping with the most vulnerable site for orbital trauma. Interestingly the average age of male patients with trauma was 29 years $(n=13)$ and without was 38 years $(n=8)$ while the opposite was shown for female patients with average age for trauma 50 years $(n=3)$ and no trauma 27 years $(n=5)$. There were 10 macula-off and 22 macula-on retinal detachments at presentation, and reattachment procedures comprised: 28 conventional (external) procedures (external drainage in 14 or $50 \%$ ), one vitrectomy and one combined vitrectomy/conventional procedure, and two cryotherapy only (asymptomatic fellow eyes). Final retinal reattachment was $100 \%$; however, eight eyes $(25 \%)$ required further procedures (two barrier laser, two vitrectomy, four further conventional procedures). All 'macula-on' patients retained visual acuity better than or equal to presentation, with $19 / 22(86 \%)$ seeing $6 / 12$ or better. 'Macula-off' patients also did well with all patients ending up better than or equal to presenting acuity and $60 \%$ regaining $6 / 24$ or better vision; however, two patients with longstanding detachments remained CF/ HM visual acuity despite successful reattachment surgery. With the exception of one patient, follow-up data was complete on all patients.

\section{Discussion}

Nonpenetrating or blunt ocular trauma, orbital trauma and systemic trauma may cause a variety of anterior and posterior segment abnormalities. ${ }^{3}$ While trauma is common, fortunately retinal tear and detachment due to trauma is uncommon. ${ }^{1}$ Because of the low prevalence of retinal detachment after trauma, an incomplete/ inadequate examination might seem to rarely result in an unfavourable outcome. Such an approach, however, is not good practice, as every patient visit is an opportunity to exclude serious pathology and prevent adverse outcomes for patients. However, this requires that appropriate examinations based on current scientific knowledge be tailored to the clinical situation. ${ }^{2,5,12,13}$ Thus, our goal in this review to determine whether established gold standard examinations in trauma patients were being satisfactorily performed in our department.

Retinal dialyses account for approximately $75 \%$ of retinal breaks after trauma and are present in up to $85 \%$ of traumatic retinal detachments. ${ }^{5,13}$ Clinical examination and histopathologic evidence suggests that most retinal dialyses result from blunt ocular trauma, ${ }^{4,12}$ although a definite history of trauma is only obtained from about $60 \%$ of patients. ${ }^{14}$ Our series supports previous findings that a history of trauma is more likely to be obtained in patients presenting with superior and/or nasal dialyses $(\sim 90 \%)$ than patients with inferior and/or temporal dialyses $(\sim 56 \%)$. ${ }^{2,14}$ This possibly reflects that a greater force is necessary to cause a dialysis superonasally with compression of the globe against the superonasal orbit, and consequently an injury more likely to be remembered. Whereas less force may be necessary to induce the more commonly found dialysis inferotemporally, where the globe occupies a more exposed position within the orbit: such injuries might therefore be easily forgotten or denied. Genetic weakness in the inferotemporal quadrant is not an important factor in the development of most retinal dialyses, which, like our group, frequently have associated ocular trauma., ${ }^{4,12}$ Whether trauma is the underlying cause or just precipitant in inferotemporal cases is less clear as lattice degeneration or some other nongenetic, developmental anomaly at the ora serrata has been implicated in some idiopathic and bilateral cases. ${ }^{2,12,15}$ Bilateral dialyses can occur in about $10 \%$ of patients, as with our group, although previous reports suggest that there is less of an association with underlying trauma in this group. ${ }^{2}$ Thus, although trauma and nongenetic developmental anomaly are the predominant associations of retinal dialysis, there is a definite subpopulation in which genetic predisposition is present. When a patient with bilateral nontraumatic retinal dialyses is discovered, other family members should be examined. ${ }^{16,17}$ Furthermore, the frequency of bilateral disease mandates examination of the fellow eye, as asymptomatic fellow eye disease may exist and may be amenable to simple retinopexy. 
It has been suggested that many of those cases of retinal detachment due to dialyses with no reported trauma, reflect forgotten or denied trauma, ${ }^{14}$ and that women acknowledge trauma less frequently than men, possibly because of a sociologic tendency for women to deny physical abuse. ${ }^{2}$ Our own results also revealed women less frequently reported trauma (38 vs 57\%) and interestingly trauma was only reported by older women.

Given the strong association of retinal dialysis with trauma, not only should patients presenting with anterior segment trauma such as hyphaema be examined for posterior segment injury, it is prudent to examine patients presenting with retinal dialysis for other sequelae of trauma. Zion and Burton ${ }^{2}$ studied 196 retinal dialysis patients and found $12 \%$ had ocular hypertension exceeding $22 \mathrm{mmHg}$ and $16 \%$ had angle recession. Angle recession is more easily diagnosed by gonioscopy in the first few weeks after trauma as trabecular lesions tend to scar and can become much more difficult to recognize over the ensuing weeks. ${ }^{9}$ Recognition of angle recession and management of ocular hypertension is important as about $5 \%$ of patients with angle recession will develop glaucoma. ${ }^{8}$ It was an interesting fact to find that only one patient of our 29 (3\%) had documented gonioscopy at any time at or after their presentation.

While necrotic retinal breaks after trauma commonly present with immediate retinal detachment, retinal dialyses often have delayed presentation. ${ }^{5}$ Thus, even though dialyses are typically present at or soon after trauma, the mean time to presentation is 8 months after trauma. ${ }^{5}$ Previous reports suggest visual prognosis is good when retinal break or detachments were diagnosed within 6 weeks of injury. However, those patients who escaped initial retinal examination (either by failed presentation, or inadequate retinal examination) or were lost to follow-up had a less favourable visual outcome. ${ }^{5}$ External procedures (scleral buckling techniques) have high success and typically low PVR rates, ${ }^{6}$ although some cases may be amenable to simple retinopexy (cryotherapy or laser). Pneumatic retinopexy offers a less-invasive alternative to scleral buckling surgery in certain cases of superior retinal dialyses. ${ }^{18}$

Our retinal reattachment rates and visual outcomes were comparable with previously reported studies. ${ }^{5,6}$ Unfortunately, a significant percentage of retinal dialysis patients present with chronic inferior retinal detachments with demarcation lines, retinal cysts, peripheral microcystoid degeneration, and yellow-white vitreous opacities, ${ }^{15}$ and remain asymptomatic until their macula detaches. Unfortunately, visual prognosis in the maculaoff setting is worse. Therefore, ophthalmologists can help prevent delayed consequences of trauma by including gonioscopy and peripheral retinal examination (indented scleral examination) in all cases of blunt trauma. ${ }^{10,11}$
Our audit provided the catalyst for a review in our education process seeking assimilation of indented peripheral retinal examination and gonioscopy (by suitably experienced ophthalmologists) into routine management practice of patients presenting to our ophthalmic casualty unit with a history of blunt trauma. It also reinforced the need to document accurately examinations performed and clinical findings. In the era of increasing medicolegal claims, the failure to adequately document that such examinations have occurred, implicates an incomplete examination, even when a comprehensive examination might have taken place. It is hoped these process changes will positively impact the results of similar future audits in our department.

\section{References}

1 Scott JD. Retinal dialysis. Trans Ophthalmol Soc UK 1977; 97(1): 33-35.

2 Zion VM, Burton TC. Retinal dialysis. Arch Ophthalmol 1980; 98(11): 1971-1974.

3 Williams DF, Mieler WF, Williams GA. Posterior segment manifestations of ocular trauma. Retina 1990; 10 (Suppl 1) S35-S44.

4 Ross WH. Traumatic retinal dialyses. Arch Ophthalmol 1981; 99(8): 1371-1374

5 Johnston PB. Traumatic retinal detachment. Br J Ophthalmol 1991; 75(1): 18-21.

6 Kennedy C, Parker C, McAllister I. Retinal detachment caused by retinal dialysis. Aust NZ J Ophthalmol 1997; 25(1): 25-30.

7 Canavan YM, Archer DB. Anterior segment consequences of blunt ocular injury. Br J Ophthalmol 1982; 66(9): 549-555.

8 Salmon JF, Mermoud A, Ivey A, Swanevelder SA, Hoffman $\mathrm{M}$. The detection of post-traumatic angle recession by gonioscopy in a population-based glaucoma survey. Ophthalmology 1994; 101(11): 1844-1850.

9 Herschler J. Trabecular damage due to blunt anterior segment injury and its relationship to traumatic glaucoma. Trans Am Acad Ophthalmol Otolaryngol 1977; 83(2): 239-248.

10 Filipe JA, Barros H, Castro-Correia J. Sports-related ocular injuries. A three-year follow-up study. Ophthalmology 1997; 104(2): 313-318.

11 Charfi Ben Ammar O, Chaker N, Soukah M, Asmi W, El Matri L et al. Posttraumatic glaucoma. J Fr Ophthalmol 2002; 25(2): 126-129.

12 Archer DB, Canavan YM. Contusional eye injuries: retinal and choroidal lesions. Aust J Ophthalmol 1983; 11: 251-264.

13 Ross WH. Retinal dialysis: lack of evidence for a genetic cause. Can J Ophthalmol 1991; 26(6): 309-312.

14 Smiddy WE, Green WR. Retinal dialysis: pathology and pathogenesis. Retina 1982; 2(2): 94-116.

15 Kinyoun JL, Knobloch WH. Idiopathic retinal dialysis. Retina 1984; 4(1): 9-14.

16 Brown GC, Tasman WS. Familial retinal dialysis. Can J Ophthalmol 1980; 15(4): 193-195.

17 Vaiser A, Jost BF. Bilateral inferotemporal dialysis in identical twins. Ann Ophthalmol 1992; 24(10): 378-380.

18 Melgen SE, Michels M. Pneumatic retinopexy for the treatment of giant retinal dialyses. Am J Ophthalmol 1994; 118(6): 762-765. 